\title{
2 INFORMATION TECHNOLOGY DIFFUSION RESEARCH: An Interim Balance
}

\author{
Karlheinz Kautz \\ Helle Zinner Henriksen \\ Toke Breer-Mortensen \\ Helle Helweg Poulsen \\ Copenhagen Business School \\ Copenhagen, Denmark
}

\begin{abstract}
In this article, we review the work of the IFIP TC8 WG 8.6 on Diffusion and Transfer of Information technology in the period 1993 through 2003. Starting with working group's aim and scope declaration, we analyze the 113 contributions that have been published in the seven conference proceedings of the group. While we can conclude that the group by and large works toward and within its own aim and scope declaration. we also find the group as of yet has no joint terminology and no shared theoretical basis. These are challenges which the group should take up in its future work.
\end{abstract}

\section{INTRODUCTION}

The first work in information technology diffusion research can be found in the late 1970s (Perry and Kraemer 1978). New technological possibilities and the wide-spread use of IT in the 1980 s then led to growing attention to the topic in various academic disciplines and commercial sectors. This is reflected in the foundation of three different interest groups in the field of IT diffusion. The IEEE Computer Society has a special interest group on Software Engineering Technology Transfer, which can be traced back to the early 1980s, while members of the Information Systems community in 1988 founded the Diffusion Interest Group in Information Technology (DIGIT). After a pilot conference in 1993, IFIP TC 8 approved their working group, 8.6, on Transfer and Diffusion of Information Technology in 1994 (referred to here as the working group or simply the group). The group tries to bridge the gap between the software engineering 
and the IS communities. It consists of about 30 regular members and its main joint activity is a working conference, held approximately every 18 months. The group has thus far had seven conferences which have been attended by about 420 delegates.

As an official IFIP organization, the group has an approved aim and scope document defining its objective: "To foster understanding and improve research in practice, methods, and techniques in the transfer and diffusion of information technology within systems that are developed and in the development process." The range of the group's work is further detailed in 10 statements covering its scope.

We take this declaration as our starting point and ask whether the group is relating its work to its declaration and whether it works toward achieving the formulated objectives. We are also interested whether there are any significant trends visible in the group's work across time. The objective of this paper is to analyze if the actual work undertaken in the group as reflected in the proceedings of the conferences corresponds to the IFIP WG 8.6 declaration. Other researchers (Fichman and Kemerer 1999; Prescott and Conger 1995; Wolfe 1994) have provided overviews of IT diffusion research in general. Wolfe (1994), in particular, has provided recommendations to researchers concerning the further development of the field. We are more interested in providing an overview of the work by the group than in outlining specific guidance as to what the community should do in future research. This search for an identity or even a paradigm within a research community resembles the debate that has taken place in the IS community as a whole as reflected in Volume 12 of Communications of AIS (articles 30 through 42). The contribution of this paper is, hence, a methodological voyage rather than a set of normative recommendations to how the group should act in the future.

The paper will proceed as follows. In the next section, we will explain the research method that will help us to answer the questions posed above. In section 3 , we will present our results, which will be discussed in section 4 , and we will end with a number of conclusions in section 5 .

\section{RESEARCH METHOD}

The overall research method we apply is that of a literature study. In the seven previous working conferences (Levine 1994; Kautz and Pries-Heje 1995; McMaster et al. 1997; Larsen et al. 1998; Ardis and Marcolin 2001; Bunker et al. 2002; Damsgaard and Henriksen 2003), the group has published a total of 113 scientific contributions. These are analyzed with regard to the group's aim and scope declaration. However, instead of taking the aim preamble and all 10 scope statements into account, we concentrate on the two main statements defining the range of the group's work as dealing with "diffusion, transfer, and implementation of both mature and immature information technologies and systems in organizations and among organizations, sectors, and countries" and the "development of frameworks, models, and terminology for information technology transfer and diffusion." To operationalize the aim and scope declaration we use the following dimensions to code and analyze the articles: terminology used, types of technology, unit of analysis, and nature of exploration. To be able to further reflect on these dimensions, we decided to take a closer look at the 
research approach and the research methods used in the work in general and across some of the dimensions. These six dimensions are briefly introduced next.

\subsection{Terminology Used}

Terminology development is explicitly mentioned in the aim and scope document. Prescott and Conger (1995) point out a need to clarify concepts and terms that are used within IT diffusion research. With the starting point being their list of concepts used, we developed a classification including includes the terms that we found during our coding and analysis. The following classes were identified: (1) adoption, (2) diffusion, (3) implementation, (4) introduction, (5) transfer, (6) adaptation, (7) assimilation, (8) acceptance, (9) routinization, (10) institutionalization, and (11) others. The last category includes terms such as absorption, appropriation, deployment, penetration, transition, spreading, and uptake, which were less frequently mentioned. In our investigation, we look at which of these are used and which are defined before usage through the work of the group. For our analysis, it should be noted that an article can contain several of these terms.

\subsection{Types of Technology}

Information technology including information systems and information technologies in the development process are explicitly mentioned in the aim and scope and lie at the center of what defines IT research (Benbasat and Zmud 2003). Although both Swanson (1994) and Lyytinen and Rose (2003) provide a classification of IT innovation, we could not find a scheme that covers the way the group deals with the information technology concept, thus we followed the strategy of Barothy et al. (1995) and developed a typology during coding and analysis. It resulted in the following classes:

- Information and information systems technologies in general: these were works with a broad focus on IT/IS without a particular emphasis on a specific technology or system type

- Interorganizational IT such as interorganizational information systems in general, for example, EDI

- Networked technologies like Internet or Web technologies, e-commerce, egovernment, or e-service technologies, CSCW or groupware systems, and IT infrastructur

- Diverse technologies, which focus on particular technologies beyond those mentioned already

- Software development technologies such as methods, techniques, CASE or other software tools, and approaches and methods for software process improvement 
Finally, we identified articles that dealt with the concept of IT outsourcing as a technology concept and articles that did not deal with technology at all.

\subsection{Unit of Analysis}

The unit of analysis is explicitly mentioned in the aim and scope with a focus on "organizations and among organizations, sectors, and countries." We did not find any appropriate classification in the literature beyond Glasson (1994), which was part of the data material, thus we developed one during coding and analysis. Beyond the four units mentioned-organization, interorganizational, sector, and country-we found articles dealing with individuals, a particular region, the specific class of academia to practice diffusion, a class of others covering diffusion from producers to suppliers or to third world countries, and a final class of "not applicable," covering conceptual articles without a particular unit of analysis. Again, articles could have several units of analysis.

\subsection{Nature of Exploration}

The nature of exploration is mentioned in the aim and scope declaration as development of frameworks and models. We were inspired by Saunders et al. (2002), who use the term in their study on power and information technology and distinguish between framework development, propositions developed, hypothesis testing, and research question explored. During coding and analysis we found (1) model and theory development, (2) model and theory evaluation, (3) hypothesis testing without aiming at developing or testing an explicitly described model or theory, (4) investigation of a specific research question without explicitly aiming at building or evaluating a model or theory, and (5) self-reflective explorations, which reflect over the work of the group or the nature of the IT diffusion research field.

A special case of theory and model development and evaluation is the utilization of Rogers' theory of diffusion of innovations first published in 1962 and since then refined in five editions of his seminal book. It has been claimed that he is one of the most important researchers in the field of diffusion in general and that he has had quite an influence on IT diffusion research (McMaster and Kautz 2002). To verify this claim, we investigate whether the group's contributions base their work directly and uncritically on Rogers, are critical of Rogers' work, refer neutrally to Rogers without taking a stand on his work, or do not refer to his work at all.

\subsection{Research Approach}

To get beyond the simplistic distinction of the positivist and the interpretive research paradigms, we align with Schultze and Leidner (2002) who, when studying the concept of knowledge management in IS, apply Deetz's (1996) framework on scientific discourse and distinguish a normative, interpretive, critical, and dialogical discourse in research. Instead of looking for contradistinctions, which bears little fruit, the intent of the framework is to direct attention to meaningful differences and similarities among 
different research activities. In the framework, the basic goal of normative research is seen in finding and defining laws, such as like relationships among objects, and in achieving progress. The interpretive research objective is to understand socially constructed constellations and to display cultures and values related to the phenomenon under investigation. Critical research aims to unmask dominance and reform social order while dialogical research strives to reclaim conflict and give space to lost voices.

\subsection{Research Method}

In line with other researchers performing literature studies (Alavi and Carlson 1992; Barothy et al. 1995; Lai 1996), we classify the contributions in the data material in empirical articles, where the work was based on empirical data and nonempirical articles, which in turn are primarily based on ideas, frameworks and speculation instead of systematic observation and data collection. Empirical IT and IS research has been classified differently by different researchers. Based on the work of Orlikowski and Baroudi (1991), Alavi and Carlson (1992), Cheon et al. (1993), Claver at al. (2000), and Vessey et al. (2001), we distinguish between (1) surveys, also comprising field studies based on questionnaire instruments or interviews, (2) case studies comprising single, multiple, cross-sectional, and longitudinal case studies, (3) action research studies focusing on both scientific results and changes in the units where the research is performed, (4) secondary data studies where the researchers analyze data provided by others, and (5) other empirical methods including laboratory experiments or simulations.

\section{RESULTS}

The data material consists of the 113 conference contributions, written by more than 170 authors. Only a small group of authors have had more than one article published in the group's proceedings (nine have published two articles, and of these, four have three or more articles). The contributions can be classified in three groups. There is a group of five articles which, from our perspective, do not deal with the diffusion of IT at all but have been accepted for the group's conference series. These articles deal with user engagement, virtual cooperation, the use of a technique for problem analysis, IT strategy, and the IT market. They have not been analyzed further. The second group consists of position statements and experience reports based or not on a research approach, method, or data analysis. This group consists of 19 contributions which were mainly ( 15 articles) presented at the pilot conference in 1993 where position statements were explicitly welcomed or they were invited lectures in 1997, 2001, and 2002. These contributions are not analyzed using all dimensions. We indicate in the following presentation where they have been taken into account and where not. The third, and by far the largest, group consists of 89 articles, which we classify as analytical or synthetical contributions based on empirical or nonempirical methods; 49 use an empirical method, while 40 are based on nonempirical work. These articles are all analyzed according to dimensions. 
Table 1. All Conferences and Contributions (1993-2003)

\begin{tabular}{|c|c|c|c|c|c|c|c|c|c|}
\hline 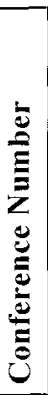 & 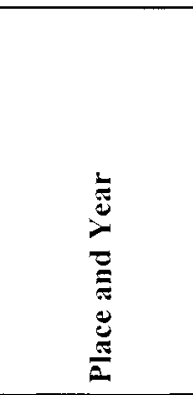 & 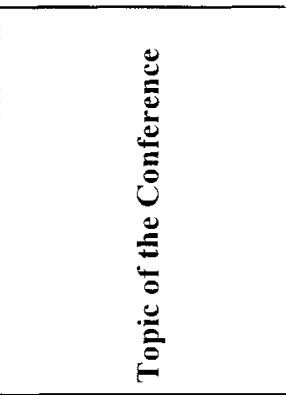 & 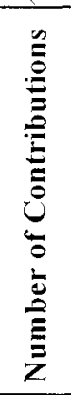 & & 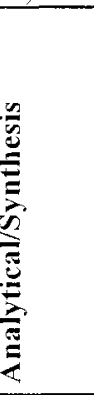 & & $\frac{\vec{E}}{\vec{E}}$ & & 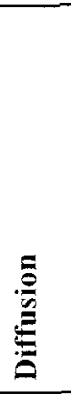 \\
\hline 0 & $\begin{array}{l}\text { Pittsburgh, } \\
\text { USA, } 1993\end{array}$ & $\begin{array}{l}\text { Diffusion, Transfer } \\
\text { and Implementation } \\
\text { of IT }\end{array}$ & 30 & 15 & $50 \%$ & 14 & $47 \%$ & 1 & $3 \%$ \\
\hline 1 & $\begin{array}{l}\text { Oslo, } \\
\text { Norway, } \\
1995 \\
\end{array}$ & $\begin{array}{l}\text { Diffusion and } \\
\text { Adoption of IT }\end{array}$ & 12 & 12 & $100 \%$ & 0 & $0 \%$ & 0 & $0 \%$ \\
\hline 2 & $\begin{array}{l}\text { Ambleside, } \\
\text { UK, } 1997\end{array}$ & $\begin{array}{l}\text { Facilitating Tech- } \\
\text { nology Transfer } \\
\text { through Partner- } \\
\text { ship: Learning } \\
\text { from Practice and } \\
\text { Research }\end{array}$ & 22 & 21 & $95 \%$ & 1 & $5 \%$ & 0 & $0 \%$ \\
\hline 3 & $\begin{array}{l}\text { Helsinki, } \\
\text { Finland, } \\
1998\end{array}$ & $\begin{array}{l}\text { Information } \\
\text { Systems: Current } \\
\text { Issues and Future } \\
\text { Changes }\end{array}$ & $8 *$ & 8 & $100 \%$ & 0 & $0 \%$ & 0 & $0 \%$ \\
\hline 4 & $\begin{array}{l}\text { Banff, } \\
\text { Canada, } \\
2001\end{array}$ & $\begin{array}{l}\text { Diffusing Software } \\
\text { Product and Process } \\
\text { Innovations }\end{array}$ & 17 & 13 & $76 \%$ & 3 & $18 \%$ & 1 & $6 \%$ \\
\hline 5 & $\begin{array}{l}\text { Sydney, } \\
\text { Australia, } \\
2002\end{array}$ & $\begin{array}{l}\text { The Adoption and } \\
\text { Diffusion of IT in } \\
\text { an Environment of } \\
\text { Critical Change }\end{array}$ & 13 & 10 & $77 \%$ & 1 & $8 \%$ & 2 & $15 \%$ \\
\hline 6 & $\begin{array}{l}\text { Copenhagen, } \\
\text { Denmark, } \\
2003\end{array}$ & $\begin{array}{l}\text { Networked IT: } \\
\text { Diffusion and } \\
\text { Adoption }\end{array}$ & 11 & 10 & $91 \%$ & 0 & $0 \%$ & 1 & $9 \%$ \\
\hline \multicolumn{3}{|c|}{ Total } & 113 & 89 & $78 \%$ & 19 & $18 \%$ & 5 & $4 \%$ \\
\hline
\end{tabular}

*This conference was a joint IFIP TC 8 WG 8.2/8.6 conference and all contributions that did not have a clear diffusion topic are not considered in our analysis. 


\subsection{Terminology Used}

In the 108 analyzed articles, 30 different terms related to diffusion are used a total of 356 times. One article, although classified as IT diffusion research, uses none of the terms.

Only 23 articles ( 21 percent) actually define one or more of the terms used. A total of 38 definitions are provided, a number of them referring to other authors such as Rogers, thus the number of definitions developed by the authors themselves is considerable lower.

With regard to the meaning of the terms, one term (adoption) was defined with three different meanings. Adoption-a term that is not mentioned in the original aim and scope - was part of the theme of the first, fifth, and sixth conferences. For the first conference, adoption was defined as having been achieved when the decision to start the usage of an innovation or technology had been taken. Fichman and Kemerer (1994) refer to adoption as "typically defined as the physical acquisition of technical artifacts or as 'commitment' to implement the innovation." This definition is in line with many traditional definitions of adoption in the context of diffusion of innovations as put forward by Rogers (2003). For the second conference, adoption was defined as achieved when the technology was actually used in practice. As Thong and Yap (1996) put it, "adoption of IT is defined as using computer hardware or software applications to support operations, management, and decision making." Finally, for the sixth conference, Bøving and Bødker (2003) defined adoption as achieved when a technology is used in the way its designers intended.

We find that adoption is the most frequently used term. It was found in 75 of the 108 articles. The other four most-used terms are diffusion, implementation, introduction, and transfer. Together these concepts are significantly more-used than the 25 others. The first three are on average used in 50 percent of all articles. It is interesting that the concept transfer, which appears in all declaration scope statements, is only used in a little over 30 percent of the articles.

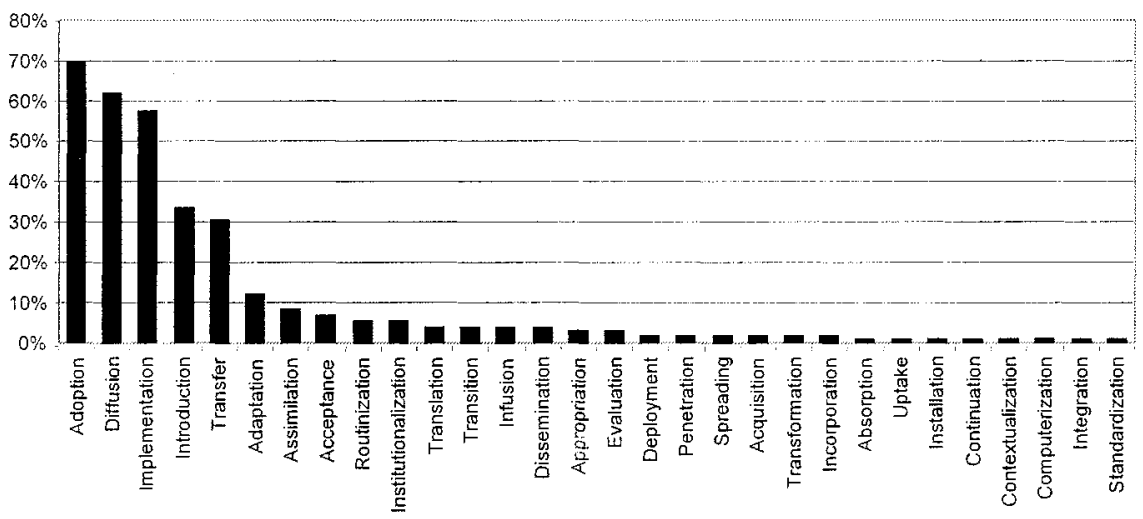

Figure 1. Percentage Use of Terms 


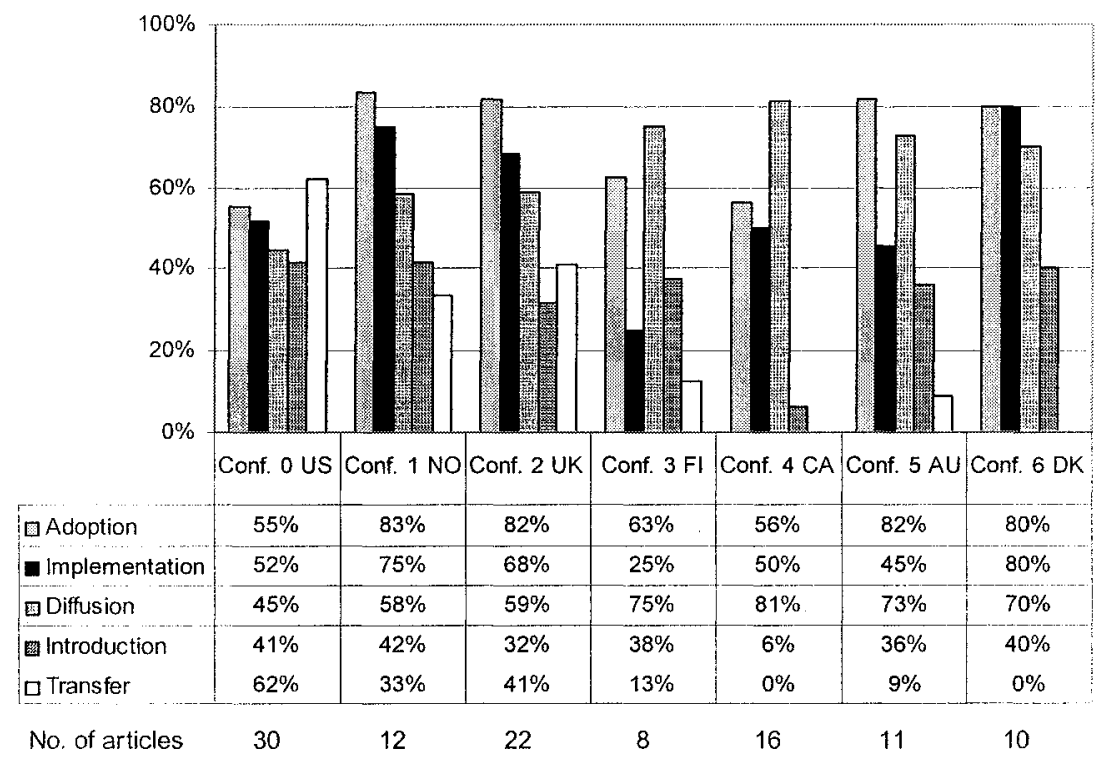

Figure 2. Use of Terms by Conference

Looking at the development over the course of the seven conferences and only taking the five most-used terms into account, it appears that the use of adoption, diffusion, implementation, and introduction is somewhat stable over time, with the first three nearly always being used. The use of the term transfer, however, declines significantly over time and is rarely or never used in the last four conferences.

\subsection{Types of Technology}

The information and information systems technologies category in general is the largest category and represents, with 38 articles, approximately a third of all contributions (see Figure 3). Software development technologies are the subject of study in 25 percent (27) of all articles. Interorganizational, network technologies, and diverse technologies are each represented in approximately 10 percent of the articles, with 9,10 , and 11 contributions, respectively. There are 11 articles that do not deal with technology at all, and a final 2 articles with IT outsourcing as a general technology concept.

Figure 4 presents the technologies per conference. Over time articles in the categories information and information systems technologies in general and software development technologies are the most-often used categories in the conferences (the pilot conference and the first through fourth working conferences). The distribution shifts, but no clear pattern can be identified. However, the number of articles in the category software development technologies decreased in the last two conferences. The category interorganizational technologies first appears in the second conference and increases slightly up to the fifth conference. IT outsourcing appears in the fifth and sixth conferences, but is a rather small category. 


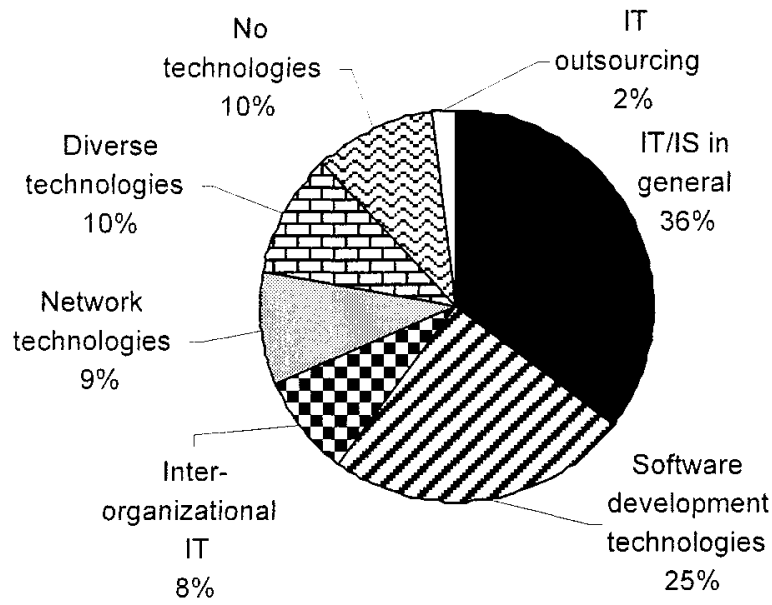

Figure 3. Types of Technology-All Conferences (108 Articles)

Across conferences, the software development technologies category appears in five out of seven conferences (the pilot conference and the second through fifth conferences) and is the dominant category at the fourth conference. This is not surprising as the theme of this conference was "Diffusing Software Product and Process Innovations."

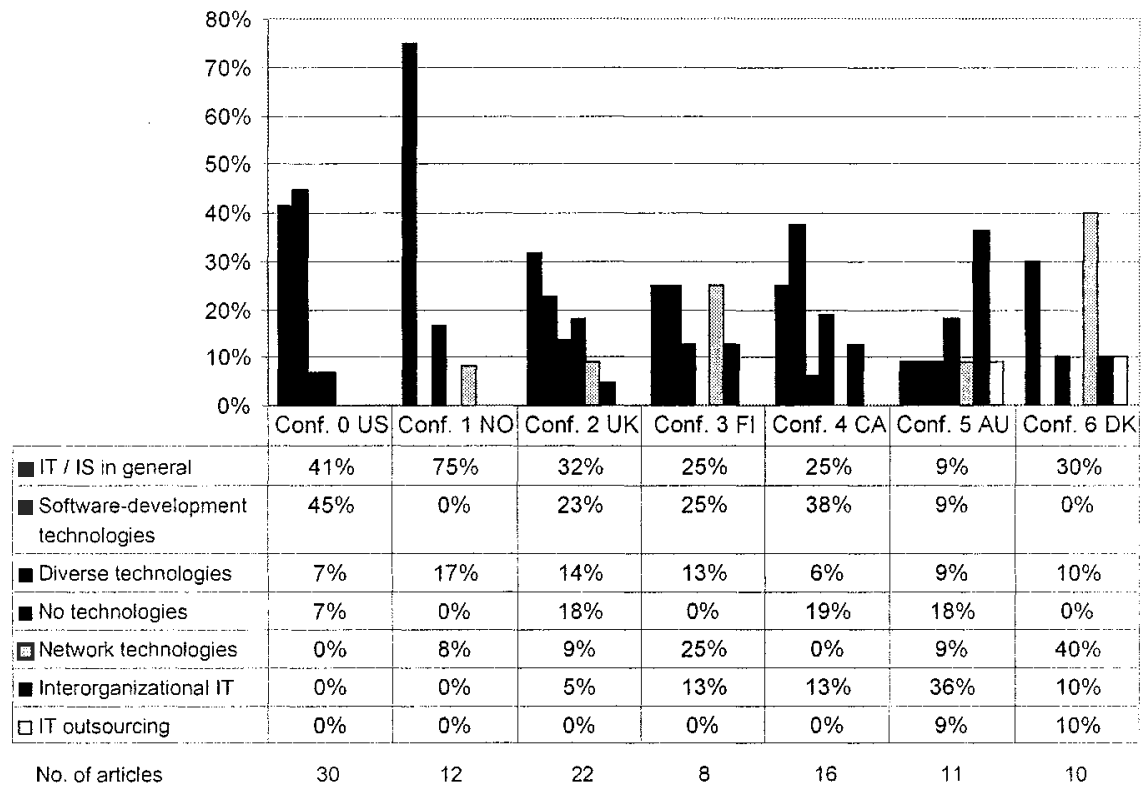

Figure 4. Technologies per Conference 
The interorganizational IT category dominated the fifth conference, while network technologies, together with information and information systems technologies in general, dominated the sixth, where the topic of the conference was "Networked Information Technology: Diffusion and Adoption." The categories interorganizational IT, diverse technologies, and no technologies are represented at the majority of conferences.

\subsection{Unit of Analysis}

Organization represents the largest category and accounts for almost two-thirds of all conference contributions ( 73 articles). All of the other categories are represented with under 10 percent each. They are distributed as follows: others, 8 articles; interorganizational, 7 articles; sector, 6 articles; country, 6 articles; not applicable, 5 articles; region, 3 articles; academia to practice, 3 articles; and individual, 2 articles. The total count of 113 articles exceeds the actual number of published articles as three articles have been classified in several categories.

The unit of analysis organization represents by far the largest category at all conferences. However, no trends, neither for the marginal shifts of this category nor for the representation of the other categories, have been found. Perhaps the category country deserves special mention here as it appears at the first four but not at the last three conferences.

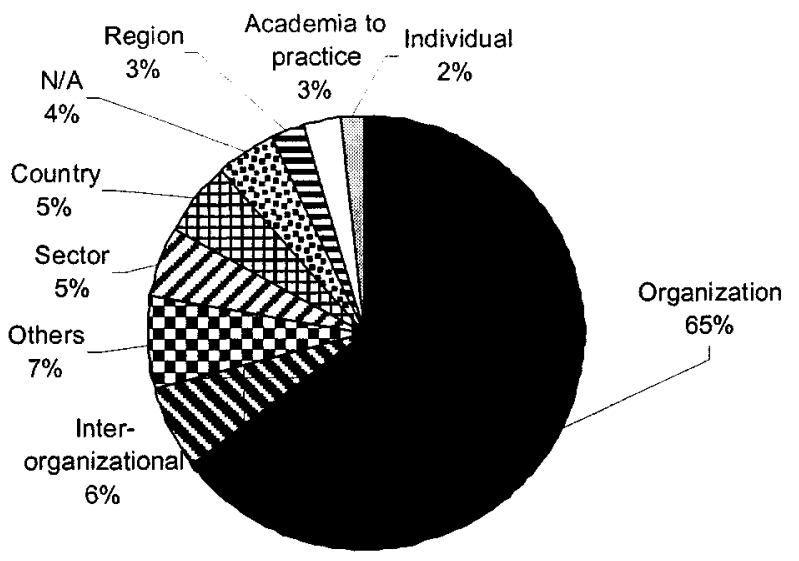

Figure 5. Unit of Analysis for All Conferences 


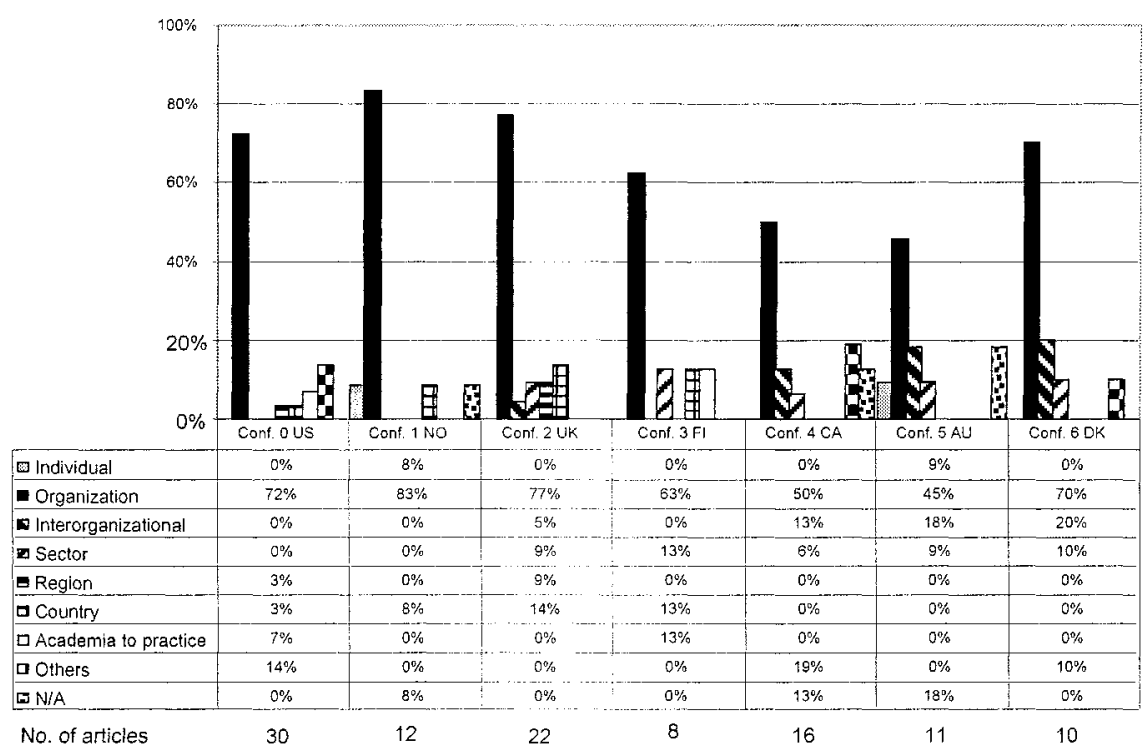

Figure 6. Unit of Analysis per Conference

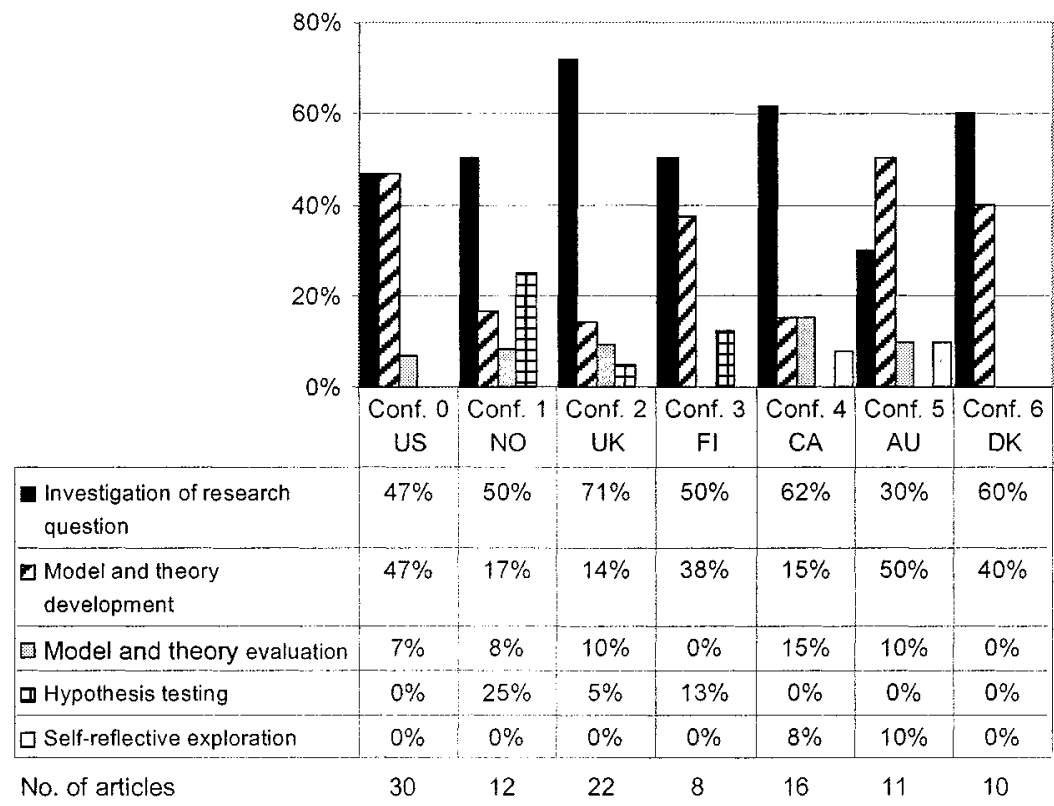

Figure 7. Nature of Exploration per Conference 


\subsection{Nature of Exploration}

Of the 89 articles categorized, those discussing position statements and those not dealing with diffusion were not considered, 49 (55 percent) investigate a specific research question, while 26 ( 28 percent) deal with model and theory development. Model and theory evaluation is a topic of seven articles ( 8 percent) and five ( 6 percent) articles test some hypothesis. Finally, two articles ( 2 percent) are concerned with self-reflection.

With the exception of the fourth conference, the investigation of a specific research question is always the largest group represented at the conferences. Hypothesis testing has not been pursued in any of the last three conferences, while the two self-reflective articles appear, naturally, at the later conferences (the fourth and fifth).

With regard to empirical and nonempirical contributions (Figure 8), 72 percent of all empirical contributions investigate a specific research question, while 14 percent deal with model and theory development; 47 percent of the nonempirical articles develop models and theories and 35 percent investigate a specific research question.

Given that the majority of articles investigate a specific research question, an investigation of the relationship between investigation of a specific research question and terminology used (Figure 9) reveals that in 74 percent of all articles investigating a specific research question the term implementation is used, adoption is used in 72 percent of these articles, while diffusion appears in 69 percent, introduction in 41 percent, and transfer in 33 percent. This means that implementation is used in 36 articles, adoption in 35 , diffusion in 34 , introduction in 20 , and transfer in 16 . The other terms play a minor role.

With regard to technology, 15 articles (32 percent) investigating a specific research question deal with information and information system technologies in general, 10 articles ( 20 percent) focus on software development technologies, 9 articles ( 18 percent) deal with diverse, and 8 articles ( 16 percent) deal with network technologies, four deal with interorganizational IT, 2 with no technology, and 1 with IT outsourcing.

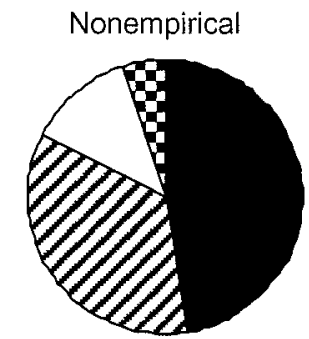

Model and theory development $47 \%$

$\checkmark$ Investigation of research question $35 \%$

$\square$ Model and theory evaluation $13 \%$

D Self reflective exploration $5 \%$

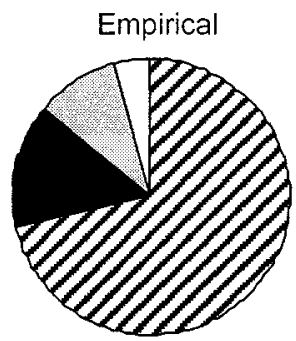

Investigation of research question $72 \%$

Model and theory development $14 \%$

口 Hypothesis testing 10\%

$\square$ Model and theory evaluation $4 \%$

Figure 8. Empirical/Nonempirical Articles According to Nature of Exploration 


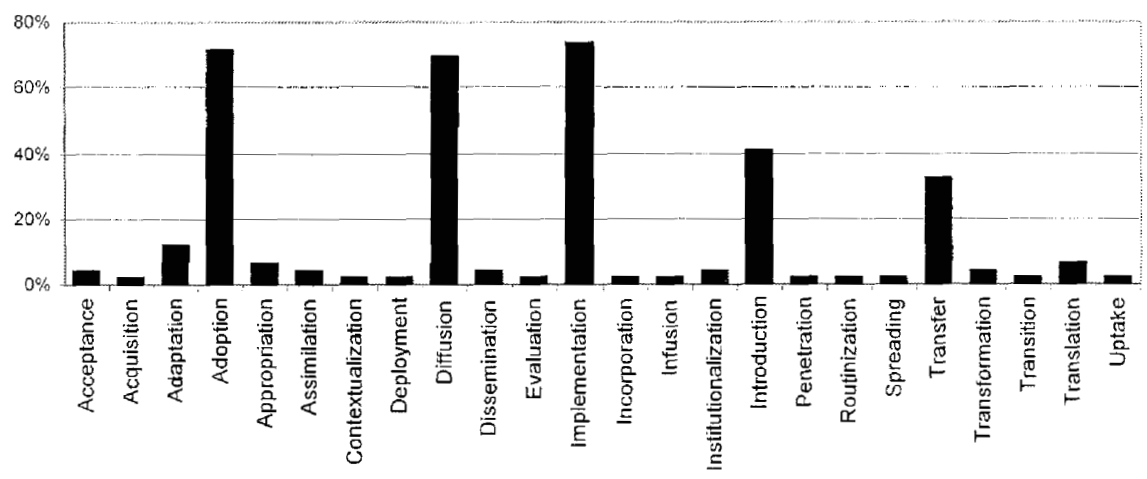

Figure 9. Terminology Used in the 49 Articles Investigating a Specific Research Question

Finally, the different units of analysis treated in work investigating a specific research question are distributed as follows: 36 are organization, 5 are interorganizational, 5 deal with an industry sector, 2 with a region, 1 with academia to practice diffusion, and 1 with something else. The relationship between investigating a specific research question and research method and approach will be described in the following two subsections.

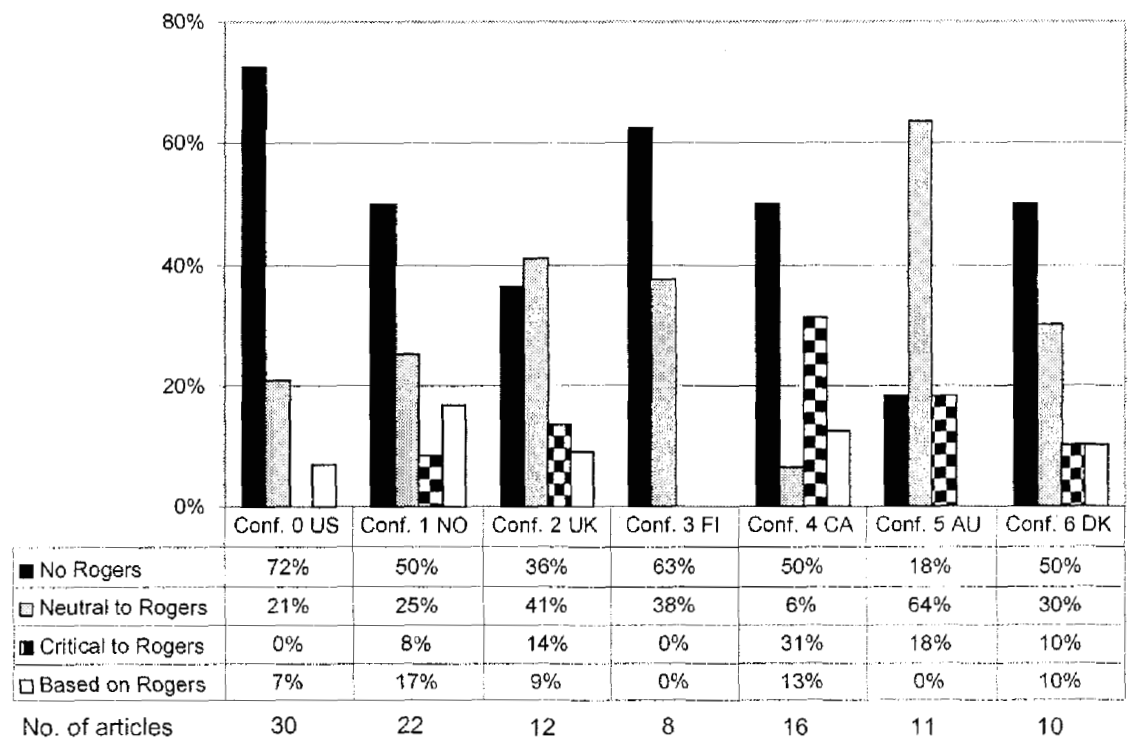

Figure 10. Categorization of Applying Rogers per Conference 


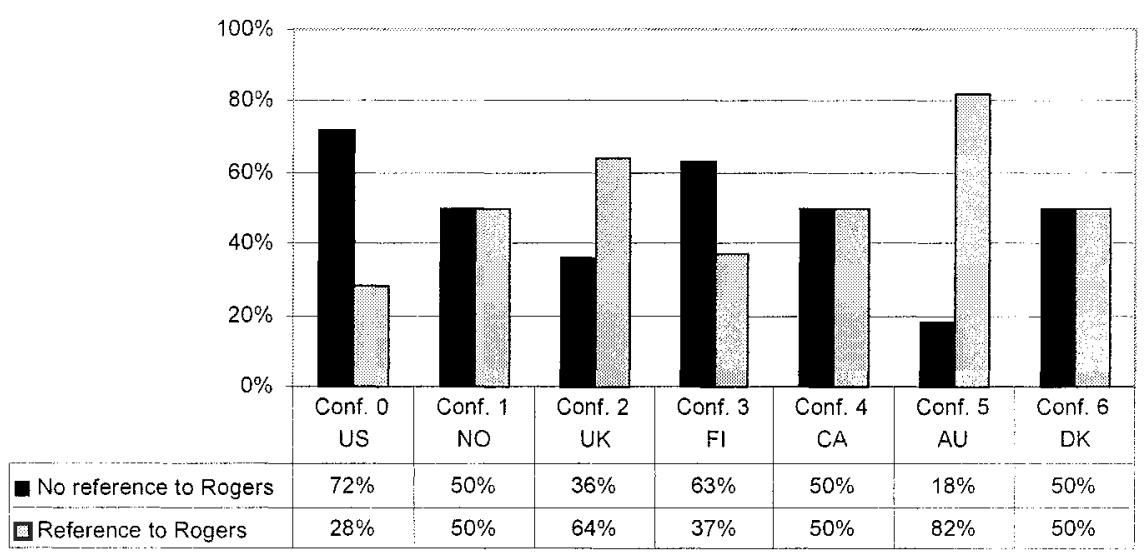

Figure 11. Articles Referring/Not Referring to Rogers

Dealing with model and theory development and evaluation the group's treatment of Rogers' work is as follows': the category not referring to Rogers is the largest, with approximately half of all articles ( 55 out of 108 , or 51 percent). The second category is neutral to Rogers, roughly one-third of all articles ( 31 out of 108 , or 29 percent); 12 articles are critical of Rogers ( 11 percent), and only 9 percent ( 10 articles) are directly based on his work. At nearly all of the conferences, the first two groups are the largest ones (with the exception of the fourth conference). Articles critical of Rogers appear at five out of seven conferences; at the third and fifth conferences, no articles were based on Rogers' work.

Finally, if we look at the distribution of articles referring to Rogers (the second and third categories) and those not doing so (Figure 11), the pilot conference has a high number of articles that do not refer to Rogers, while the fifth conference is the opposite. However, no clear trend is recognizable.

\subsection{Research Method}

Out of the 89 articles classified as research contributions, 49 use an empirical method, while 40 are based on nonempirical work. In the group of empirical research, 49 percent ( 24 articles) are case studies, 20 percent ( 10 articles) are surveys, and 15 percent ( 7 articles) are based on action research, while secondary data studies and others account for 8 percent ( 4 articles) each. With regard to the total amount of research articles, case studies, with 27 percent, comprise nearly one-third of all articles, while surveys and action research studies account for about 10 percent each.

The amount of nonempirical articles swings from 25 percent at the second conference to nearly 70 percent at the fourth conference. In total, the distribution is as shown in Figure 12.

'Here again, 108 articles, including those comprising position statements, were considered. 


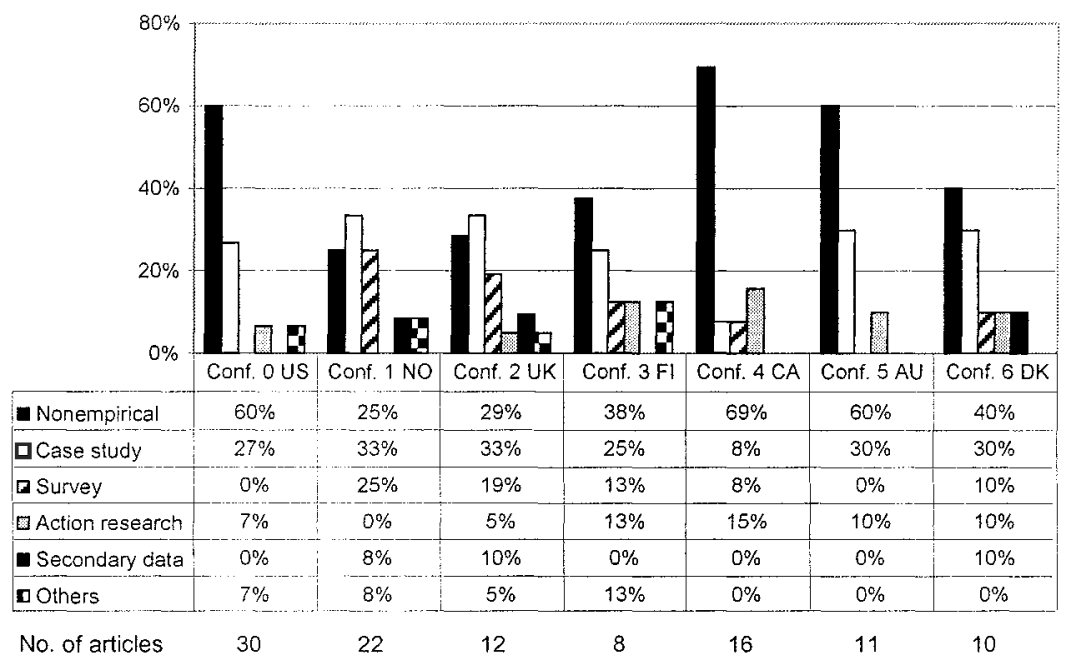

Figure 12. Classification of Research Methods per Conference

With regard to applied research method and the nature of exploration (Table 2), the distribution shows a strong dependence between case studies and the investigation of a specific research question.

Looking at research method and unit of analysis (Table 3), again case studies are the majority, especially case studies taking place in organizations.

Table 2. Research Method and Nature of Exploration

\begin{tabular}{|l|c|c|c|c|}
\hline & $\begin{array}{c}\text { Investigation of a } \\
\text { Specific Research } \\
\text { Question }\end{array}$ & $\begin{array}{c}\text { Model and } \\
\text { Theory } \\
\text { Development }\end{array}$ & $\begin{array}{c}\text { Model and } \\
\text { Theory } \\
\text { Evaluation }\end{array}$ & $\begin{array}{c}\text { Hypothesis } \\
\text { Testing }\end{array}$ \\
\hline $\begin{array}{l}\text { Case } \\
\text { studies }\end{array}$ & 18 & 4 & 2 & - \\
\hline Surveys & 6 & - & - & 4 \\
\hline $\begin{array}{l}\text { Action } \\
\text { Research }\end{array}$ & 4 & 3 & - & - \\
\hline $\begin{array}{l}\text { Secondary } \\
\text { Data }\end{array}$ & 4 & - & - & - \\
\hline Others & 3 & - & - & 1 \\
\hline Total & 35 & 7 & 2 & 5 \\
\hline
\end{tabular}


Table 3. Research Method and Unit of Analysis

\begin{tabular}{|c|c|c|c|c|c|c|c|c|c|}
\hline & 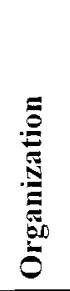 & 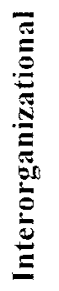 & 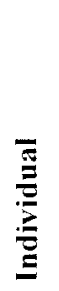 & 离 & $\underset{\mathscr{0}}{\mathscr{0}}$ & $\stackrel{\Xi}{\Xi}$ & 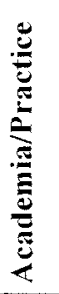 & $\frac{n}{\grave{E}}$ & $\frac{\xi}{z}$ \\
\hline $\begin{array}{l}\text { Case } \\
\text { studies }\end{array}$ & 21 & 2 & - & 1 & - & 3 & & - & - \\
\hline Surveys & 7 & - & 1 & - & 1 & 1 & 1 & - & - \\
\hline $\begin{array}{l}\text { Action } \\
\text { Research }\end{array}$ & 7 & - & - & - & - & - & - & - & - \\
\hline $\begin{array}{l}\text { Secondary } \\
\text { Data }\end{array}$ & 2 & 1 & - & - & 1 & - & - & - & - \\
\hline Other & 4 & - & - & - & - & - & - & - & - \\
\hline Total & 41 & 3 & 1 & 1 & 2 & 4 & 1 & - & - \\
\hline
\end{tabular}

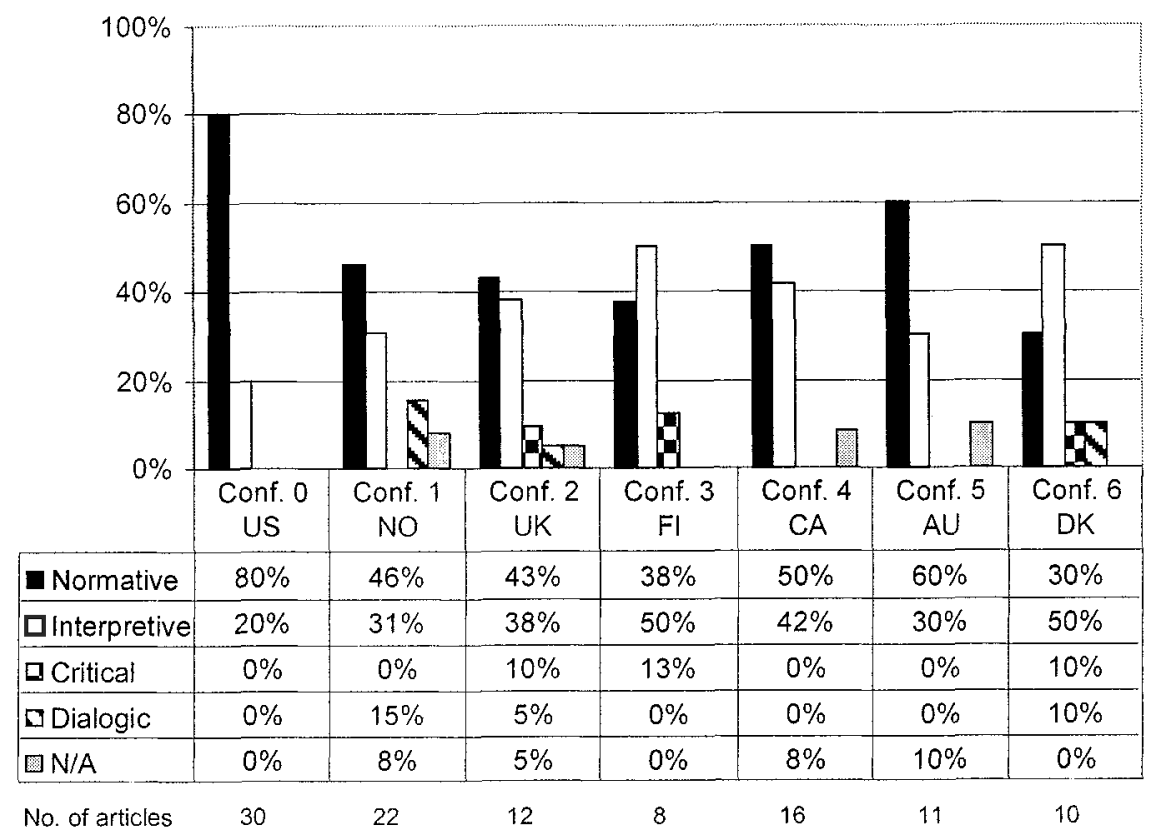

Figure 13. Classification of Research Approaches per Conference 


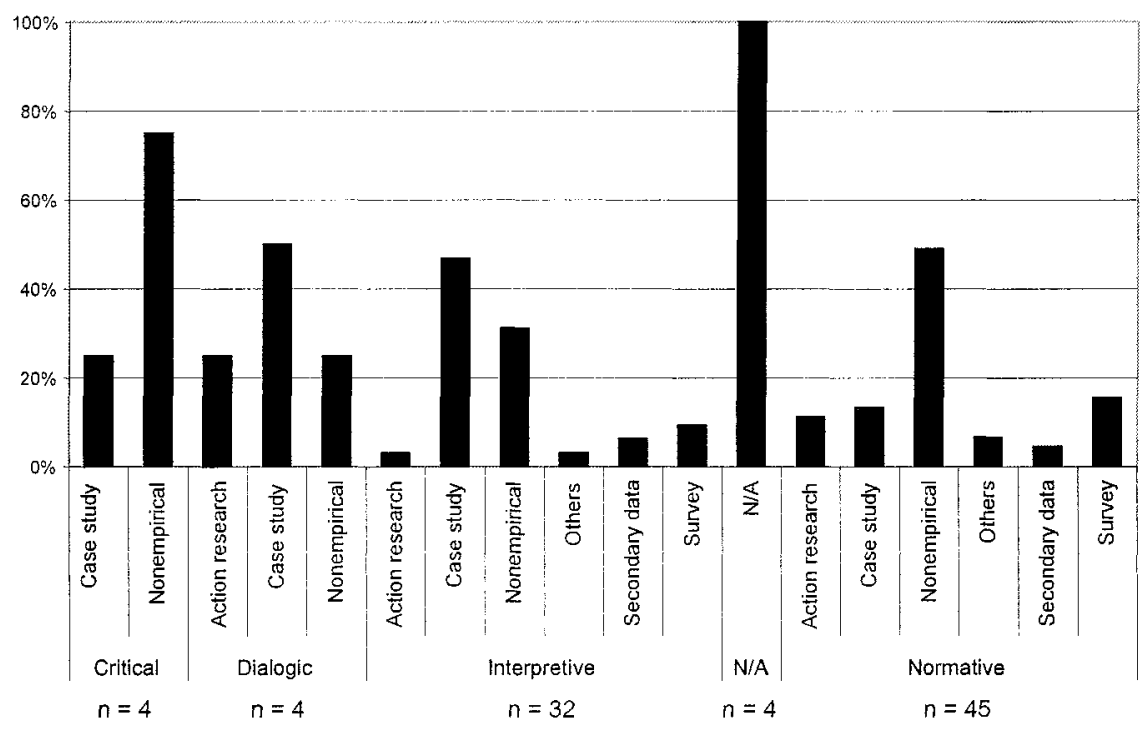

Figure 14. Relationship Between Research Approach and Research Method

\subsection{Research Approach}

The majority of the 89 research articles presents a normative discourse with 45 articles ( 52 percent); 32 articles ( 36 percent) belong to the interpretative discourse. Critical and dialogical discourses appear four times each (4 percent each), while four articles could not be classified according to the chosen framework. Normative and interpretative articles add up to more than 75 percent of all articles at all conferences, with their actual distribution swinging a bit. While the normative discourse dominates the first three conferences, the majority of contributions to the third and sixth conferences, both arranged in northern Europe, comes from the interpretive discourse.

The distribution of research methods within the four research approaches is depicted in Figure 14. In particular, Figure 14 shows that the majority of interpretive articles are case studies ( 16 articles).

The relationship between research approach and nature of exploration (Figure 15) shows that both investigation of a specific research question and model and theory development are nearly equally dominant in the normative discourse with 44 percent and 42 percent of all 45 contributions respectively while in the interpretive discourse, 72 percent of the 32 contributions deal with one specific research question and only 18 percent with model and theory development.

Finally, the relationship between research approach and unit of analysis (see Table 4) shows that both the normative and the interpretive discourse deal primarily with the organization as the unit of analysis. 


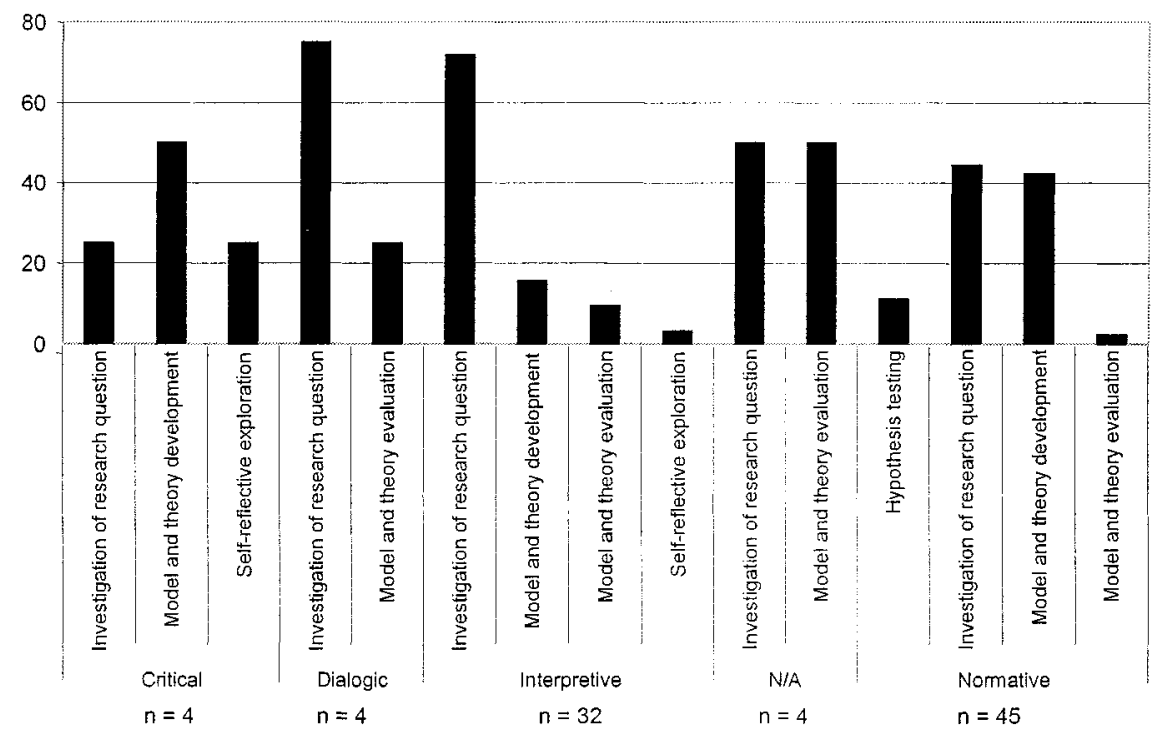

Figure 15. Relationship Between Research Approach and Nature of Exploration

Table 4. Relationship Between Research Approach and Unit of Analysis

\begin{tabular}{|c|c|c|c|c|c|c|c|c|c|}
\hline & 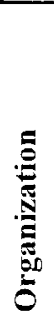 & 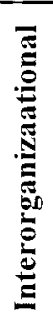 & 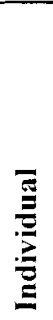 & $\stackrel{\grave{\Xi}}{\breve{J}}$ & 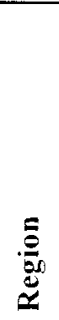 & $\underset{E}{E}$ & 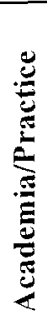 & $\stackrel{\frac{2}{E}}{E}$ & $\frac{1}{z}$ \\
\hline Normative & 33 & 2 & 2 & 2 & 1 & 2 & - & 4 & - \\
\hline Interpretive & 23 & 5 & - & 2 & 1 & 2 & 1 & 1 & 1 \\
\hline Critical & 3 & - & - & - & - & - & - & - & 1 \\
\hline Dialogical & 4 & - & - & - & - & - & - & - & - \\
\hline $\mathrm{N} / \mathrm{A}$ & 1 & - & - & 1 & - & - & - & - & 2 \\
\hline Total & 64 & 7 & 2 & 5 & 2 & 4 & 1 & 5 & 4 \\
\hline
\end{tabular}




\section{DISCUSSION}

With the group's aim and scope statement as the starting point and the results presented here, the following discussion attempts to answer two questions: Does the group work with the diffusion, transfer, and implementation of both mature and immature information technologies and systems in organizations and among organizations, sectors, and countries? Does the group work with the development of frameworks, models, and terminology for information technology transfer and diffusion?

Answering question 1, we can conclude that, yes, the group works with diffusion, transfer, and implementation. These terms are used in 62 percent (diffusion), 31 percent (transfer), and 58 percent (implementation) of all articles. Furthermore, these articles analyze implications of diffusion, transfer, or implementation of technology. The group also works with a broad spectrum of information technologies. General information and information system technologies are the largest group, being the subject of 36 percent of all articles, followed by software development technologies the topic in 25 percent.

Along with software process innovations and networked IT, specific technologies appear as topics for two conferences. This approach is in line with the aim and scope statement where, beyond information technologies and systems and software development technologies, no particular technology is mentioned or excluded. Finally, considering the unit of analysis, we can state that again, corresponding to the group's aim and scope, the dominant unit of analysis is the organization, the theme of 65 percent of all contributions, whereas diffusion, transfer, and implementation between organizations ( 7 percent), in (business and public) sectors ( 6 percent), and in countries ( 6 percent) play a minor role.

However, the results also show that the group does more than that. The term adoption, although not mentioned in the aim and scope, is in the title of three conferences and is actually the most-used term in the group's work, appearing in 70 percent of all publications. The term introduction can be found in 33 percent of all articles, making it a more frequently used term than transfer, which, although part of all $10 \mathrm{aim}$ and scope statements, was hardly ever used in the last four conferences. With regard to the overarching question of what the group should do in the future, this question can lead to different conclusions.

The group might want to change its aim and scope statement including terms like adoption and introduction and excluding the term transfer. Such a change would more precisely reflect what the group focuses on in its research

With regard to the role information technologies play in the group's work, it can be argued that having 10 percent of all articles not dealing with IT at all, but with technology-independent concepts like diffusion, might enrich the group's work, but might also be a sign of a lack of focus. Thus the group might consider no longer accepting work not dealing with IT as it falls outside the group's aim and scope. However, the latter would imply that there would be no room for self-reflection (such as this paper) or theory development independent of particular technological innovations. In this context, it is worth noticing that Rogers, referred to in 49 percent of all articles and by far the most cited author in the analyzed contributions, does not build his diffusion of innovations theory on IT innovations

Also with respect to the unit of analysis, the group goes beyond its declaration 
Although not regularly and only to a small extent, the individual, the region, diffusion from academia to practice, and from suppliers to customers account for 15 percent of the group's conference contributions. These units might also be explicitly mentioned in an augmented aim and scope statement or excluded from future conferences. Restrictions in unit of analysis could, however, result in important issues related to diffusion and implementation being missed. For future research of the group's work, it would be useful to expand the data to include literature references and affiliation of authors. One particular issue, which could be clarified if affiliation of authors were included, is the share of contributions from practitioners and from researchers from universities and business schools respectively. Practitioners and academics from business schools might be more preoccupied with the supplier-customer relationship whereas researchers from universities might be more interested other issues.

To answer the second question, let us revisit the terms used. In the group's work, 30 different terms related to diffusion are used and 38 different definitions are provided. However, only a little over 20 percent of the articles define the terms they use. For one of the more central concepts, namely adoption, at least three definitions are provided by different authors.

Thus, although it can be argued that the group works with the development of terminology, this seems to be a limited and largely individual, fragmented, and rather uncoordinated endeavor. Parts of this fragmented effort might be explained by the methodological approach of the researchers. Positivists and interpretivists rarely have a common understanding of the deeper meaning of terms and in particular the implications of specific terms. This is clearly illustrated by the example of the term adoption, where the positivist view is represented by Rogers' definition, whereas Bøving and Bødker (2003) represent the interpretivist view on the meaning of the term. However, the methodological stance of the researchers does not excuse that most of the group's work is performed without a definition of the central terms. It would be desirable at the group level to put an effort into a common development of terminology. This is definitely a task that has to be taken more seriously in the future.

The development of frameworks and models can be assessed by looking at the nature of exploration of the group's work. The majority of the articles, 55 percent, is based on investigating a specific research question. While these articles might deal with the development of frameworks or models for a specific aspect of IT diffusion, and thus can be said to contribute to a larger body of knowledge in the field, a comparative analysis of these 49 contributions leading to more general, broader frameworks, models, or theories of IT diffusion has not taken place. Theory development and evaluation including hypothesis testing is the subject of 42 percent of the 89 research-based articles of the group.

In this context it also has to be emphasized that Rogers' framework does not serve the group as a joint starting point or theoretical basis; on the contrary, more than 50 percent of all articles do not even refer to his work. Whether this is out of ignorance or for other reasons cannot be said on the basis of our data. As emphasized earlier, one reason for this could be that Rogers' theory is not directly related to IT innovations.

Again, the argument can be made about the fragmented nature of the group's work and its lack of focus on theory development in the traditional sense. However, although stated in the aim and scope, frameworks, and models, and for that matter traditional 
theory development, might not be the objective or primary ambition of all group members. Out of the 89 scientific articles, only 52 percent are classified as belonging to the normative discourse with its pursuit of causal logic-based theories, whereas 36 percent subscribe to an interpretive tradition aimed primarily at understanding complex phenomena. Even in the normative approach, theory and model development and the investigation of a specific research question are nearly equally represented, with the latter being, by a small margin ( 44 percent versus 42 percent), the strongest. This lack of theory can be seen as a weakness of the group, but can also be explained by the relative youth of the field, where the investigation of single questions precedes general methodologies. The group members' interest are mirrored in the interpretive approach, with 32 contributions, where the investigation of a specific research question clearly dominates, with 72 percent, over theory development, with 18 percent. Finally, this is supported by the fact that case studies--usually more associated with understanding than with law like logic (Zmud et al. 1989)-with 27 percent is the research method of nearly one-third of all articles. While not surprising, 48 percent of all interpretive contributions are based on case studies, with 12 percent of the normative articles having a case study background and thus possibly an interpretive element.

With regard to the group's future, this might mean that limiting the group's work to what is more or less explicitly described in the aim and scope is one possibility to deal with the situation. Another way is to broaden the scope by explicitly including theory development in an extension of framework and model development in the aim and scope declaration, but simultaneously clarifying what is meant by theory with regard to the different discourses.

However, as a consequence, this also means that--beyond continuing empirical work and the 22 articles, which were within the normative approach based on nonempirical methods - to further develop the field of IT diffusion theoretically, the group needs to perform more conceptual and theoretical work within the interpretive, critical, and dialogical discourse.

\section{CONCLUSION}

Based on the above analysis and discussion, we can conclude that the group works toward and within its own aim and scope declaration. There are, however, a number of challenges. The group has no joint terminology and no shared theoretical basis. An expansion of the aims of IFIP WG 8.6 could, therefore, explicitly be to focus on diffusion terminologies and theory development within the realm of IT/IS research.

Like many educational organizations, the group can be considered as a system of loosely coupled individuals, who as semiautonomous participants strive to maintain a degree of independence while working under the name and framework of the organization to pursue their personal goals (Morgan 1986; Weick 1976). As such, a tooexclusive aim and scope statement might hinder the group in extending the body of knowledge. However, beyond researching new technologies like mobile information systems and management fashions and fads like business agility, the group should stay with its roots and work to explicitly contribute to IT diffusion theory and terminology.

To further explore the argument of how deeply the group is actually rooted in the 
normative discourse, a more detailed investigation of the authors of normative contributions is necessary to find out whether these authors only pass by the group with one publication or whether they belong to the kernel of the group. To do this, however, a clarification of who constitutes the group might be useful, given that only few registered members publish regularly at the group's conference.

Future research should also look into the degree of internal references within the group, but in addition study the extent of other common literature references, which might define a shared and common (back)ground for the group. We have made an attempt to do so, but the inconsistency of the current data material in this respect does not yet allow for any conclusions. Thus, here also lies a challenge for the group in its pursuit of advancing IT diffusion research.

\section{REFERENCES}

Alavi, M., and Carlson, P. "A Review of MIS Research and Disciplinary Development," Journal of Management Information Systems (3:4), 1992, pp. 45-62.

Ardis, M. A., and Marcolin, B. L. (Eds.). Diffusing Software Product and Process Innovations, Boston: Kluwer Academic Publishers, 2001.

Barothy, T., Peterhans, M., and Bauknecht, K. "Business Process Reengineering: Emergence of a New Research Field," SIGOIS Bulletin (16:1), 1995, pp. 3-10.

Benbasat, I., and Zmud, R. W. "The Identity Crisis within the IS Discipline: Defining and Communicating the Discipline's Core Properties," MIS Quarterly (27:2), 2003, pp. 183-194.

Bunker, D., Wilson, D., and Elliot, S. (Eds.). The Adoption and Diffusion of IT in an Environment of Critical Change, Sydney, Australia: Pearson Publishing Service Australia (on behalf of IFIP), 2002.

Bøving, K. P., and Bødker, K. "Where Is the Innovation," in Networked Information Technologies: Diffusion and Adoption, J. Damsgaard and H. Z. Henriksen (Eds.), Boston: Kluwer Academic Publishers, 2003, pp. 39-52.

Cheon, M. J, Grover, V., and Sabherwal, R. "The Evolution of Empirical Research in IS: A Study in IS Maturity," Information \& Management (24), 1993, pp. 107-119.

Claver, E., González, R, and Llopis, J. "An Analysis of Research in Information Systems (19811997)," Information \& Management (37), 2002, pp. 181-195.

Damsgaard, J, and Henriksen, H. Z. (Eds.). Networked Information Technologies: Diffusion and Adoption, Boston: Kluwer Academic Publishers, 2003.

Deetz, S. "Describing Differences in Approaches to Organization Science: Rethinking Burrell and Morgan and Their Legacy," Organization Science (7:2), 1996, pp. 191-207.

Glasson, B. C. "Toward a National Information Systems and Technology Research and Development Association," in Diffusion. Transfer and Implementation of Information Technology, L. Levine (Ed.), Amsterdam: North-Holla,d 1994, pp. 333-345.

Fichman, R. G., and Kemerer, C. F. "The Illusory Diffusion of Innovation: An Examination of Assimilation Gaps," Information Systems Research (10:3), 1999, pp. 255-275.

Fichman, R. G., and Kemerer, C. F. "Toward a Theory of the Adoption and Diffusion of Software Process Innovations," in Diffusion, Transfer and Implementation of Information Technology, L. Levine (Ed.), Amsterdam: Elsevier Science, 1994, pp. 23-30.

Kautz, K., and Pries-Heje, J. (Eds.). Diffusion and Adoption of Information Technology, London: Chapman \& Hall, 1995.

Lai, V. S. "An Assessment of Database Research Interest in MIS," The Data Base for Advances in Information Systems (27:2), 1996, pp. 37-43. 
Larsen, T. J., Levine, L., and DeGross, J. I. (Eds.). Information Systems: Current Issues and Future Changes, Laxemburg, Austria: IFIP Press, 1988.

Levine, L. (Ed.). Diffusion, Transfer and Implementation of Information Technology, Amsterdam: North-Holland, 1994.

Lyytinen, K., and Rose, G. M. "The Disruptive Nature of Information Technology Innovations: The Case of Internet Computing in Systems Development Organizations," MIS Quarterly (27:4), 2003, pp. 557-595.

McMaster, T., and Kautz K. "A Short History of Diffusion," in The Adoption and Diffusion of IT in an Environment of Critical Change, D. Bunker, D. Wilson, and S. Elliot (Eds.), Sydney, Australia: Pearson Publishing Service (for IFIP), 2002, pp. 10-22.

McMaster, T., Mumford, E., Swanson, E. B., Warboys, B., and Wastell, D. (Eds.). Facilitating Technology Transfer Through Partnership: Learning from Practice and Research, Proceedings of the IFIP TC8 WG8.6 International Working Conference on Diffusion, London: Chapman \& Hall, 1997.

Morgan, G. Images of Organization, London: Sage Publications, 1986.

Orlikowski, W. J., and Baroudi, J. J. "Studying Information Technology in Organizations: Research Approaches and Assumptions," Information Systems Research (2:1), 1991, pp. 128.

Perry, J., and Kraemer, K. L. "Innovation Attributes, Policy Intervention, and the Diffusion of Computer Applications Among Local Governments," Policy Sciences, April 1978, pp. 179205.

Prescott, M. B., and Conger, S. A. "Information Technology Innovations: A Classification by IT Locus of Impact and Research Approach." The Data Base for Advances in Information Systems (26:2-3), 1995, pp. 20-41.

Rogers, E. M. The Diffusion of Innovations ( ${ }^{\text {st }}$ ed.), New York: The Free Press, 1962.

Rogers, E. M The Diffusion of Innovations ( $5^{\text {th }}$ ed.). New York: The Free Press, 2003.

Saunders, C. S., Carte, T. A., Jasperson, J., Croes, H., Zheng, W., and Butler, B. S. "Power and Information Technology: A Review Using Metatriangulation," in Proceedings of the $27^{\mathrm{st}}$ International Conference on Information Systems, W. J. Orlikowski, S. Ang, P. Weill, H. C. Krcmar, and J. I. DeGross (Eds.), Brisbane, Australia, 2000, pp. 339-350.

Schultze, U., and Leidner, D. E. "Studying Knowledge Management in Information Systems Research: Discourses and Theoretical Assumptions," MIS Quarterly (26:3), 2002, pp. 213242.

Swanson, E. B. "Information Systems Innovation Among Organizations," Management Science (40:9), 1994, pp. 1069-1088

Thong, J. Y. L., and Yap, C. S. "Information Technology Adoption by Small Businesses: An Empirical Study," in Diffusion and Adoption of Information Technology, K. Kautz and J. Pries-Heje (Eds.), London: Chapman \& Hall, 1996, pp. 160-175.

Vessey, I., Ramesh, V, and Glass, R. L. "Research in Information Systems: An Empirical Study of Diversity in the Discipline and ITS Journal," Information Systems Technical Reports and Working Papers, TR106-1 (URL (31-07-2004), Kelley School of Business, Indiana University, 2001 (available online at http://www.kelley.iu.edu/ardennis/wp/tr1061.doc).

Weick, K. E. "Educational Organizations as Loosely Coupled Systems," Administrative Science Quarterly (21), 1976, pp. 1-19.

Wolfe, R. A. "Organizational Innovation: Review, Critique and Suggested Research Directions," Journal of Management Studies (31:3), 1994, pp. 405-431.

Zmud, R., Olsen, M. H., and Hauser, R. "Field Experimentation in MIS Research," The Information Systems Research Challenge: Experimental Research Methods Volume 2, I. Benbasat (Ed.), Boston: Harvard Business School Research Colloquium, 1989, pp. 97-112. 


\section{ABOUT THE AUTHORS}

Karlheinz Kautz, Dr. philos, is a professor of Systems Development and Software Engineering in the Department of Informatics at the Copenhagen Business School. Previously, he has been employed as a senior researcher at the Norwegian Computing Center and as a lecturer at universities in Germany, Norway, England, and Denmark. He is the chair of IFIP WG 8.6, Diffusion, Transfer, and Implementation of Information Technology. His research interests are in systems development and system development methodologies in practice, the diffusion and adoption of information technology innovations, the organizational impact of IT, knowledge management, and software quality and process improvement. He has published in these areas in joumals including Information and Software Technology, Information. Technology \& People, Scandinavian Journal of Information Systems, Software Process: Improvement and Practice, IEEE Software, Journal of Knowledge Management, Journal of Information Systems, Journal of Informing Science, and Journal of Information Technology Cases and Applications. He is a member of ACM and IEEE. Karl can be reached at Karl.Kautz@cbs.dk.

Helle Zinner Henriksen is an assistant professor in the Department of Informatics at the Copenhagen Business School. She has an M.Sc. in law from the University of Copenhagen and a Ph.D. from the Department of Informatics at the Copenhagen Business School in the field of Management of Information Systems with particular interest on the implications of institutional intervention with respect to interorganizational adoption and diffusion. Her research interests include adoption and diffusion of IT in the private and public sector. Her most recent work focuses on eGovernment and regulation of eGovernment. Helle is involved in the Center for Research on IT and Policy Organizations at the Copenhagen Business School. More details on her research activities and publications can be found at http://web.cbs.dk/staff/hzh/. She can be researched athzh.inf@cbs.dk.

Toke Breer-Mortensen was a research assistant in the project on which this research article is based. Toke recently graduated from the Copenhagen Business School's Master's program in Computer Science and Business Administration. Toke can be reached at Toke@doek.dk.

Helle Helweg Poulsen was a research assistant in the project on which this research article is based. Helle recently graduated from the Copenhagen Business School's Master's program in Computer Science and Business Administration. Helle can be reached at toke@doek.dk. 